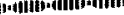
Transaction

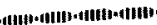

(Received August 28, 1987)

\title{
EFFECT OF PRE-STRAINING OF PAPER SHEET ON ITS SIZING EFFICIENCY
}

\author{
By Yun Long Pan. Fumihiko Onabe and Makoto Usuda
}

(Department of Forest Products, Faculty of Agriculture, the University of Tokyo, Yayoi, Bunkyo-ku, Tokyo, 113 Japan)

\begin{abstract}
The sizing efficiency of pre-strained papers were measured by Stockigt and Cobb sizing test methods. It was found that the sizing efficiency of acidic-sized papers decreases with straining of sheet, while that of alkaline-sized papers exhibits a reverse tendency. Straining level also affects sizing efficiency. However, all these changes are within $10 \%$ of the sizing degree of the unstrained paper. Effect of the factors being affected by straining, such as paper thickness and porous structure, were studied on the basis of Lucas-Washburn equation. Analysis shows that the differences between alkaline- and acidic-sized papers could be interpreted in terms of the bonding forces between pulp fibers and sizing agents, and the uniformity of distribution of the sizing agents on the fiber surfaces.
\end{abstract}

\section{INTRODUCTION}

Paper web is stretched during its manufacturing processes such as drying, rewinding and coating. It has been known that a variety of properties of paper sheets such as thickness ${ }^{1)}$. specific light scattering coefficient ${ }^{2)}$ etc., vary with stretching. The structural changes are generally explained in terms of straightening of the longitudinal fibers, the partial rupture of fiber bondings, and the separation of fiber bondings. Sizing efficiency of paper is mainly dependent on the hydrophobicity of the sheet materials, but the structural parameters such as apparent density (pore volume), thickness (capillary length) and the presence of defects also play important roles in sizing efficiency ${ }^{3), 4)}$. As the irreversible stretching of paper brings about the structural changes of paper, it will have a certain effect on the sizing efficiency.

Rance has shown that the expansion of paper on wetting is reduced by an amount proportional to the degree of permanent set caused by prestraining ${ }^{5}$. This finding suggests that changes in interfiber bondings and straightening of fibers within the sheet occur and affect its sizing efficiency. As for the changes in sizing efficiency caused by stretching of sheet, only a few works have been reported so $\mathrm{far}^{5)}$. Strained paper is generally thought to lower sizing efficiency because of an increase in the number and size of defects formed by fiber bonding breakages. However, lowering of sizing efficiency was recognized only for acidic-sized papers in this experiment. Alkalinesized paper showed a little different behavior. In any case, the effect of pre-straining of sheet on the sizing efficiency was dependent on the level of straining. The fact that the effect is relatively small even at ultimate straining level suggests that the newly formed surfaces by straining have certain level of hydrophobicity, although there are some difference in sizing efficiency between acidic-sized and alkaline-sized papers.

Bondings between cellulosic fibers and sizing agents relate the strength property of paper ${ }^{6}$. The bonding strength is thought to affect the stability of sizing efficiency on sheet stretching. In general, acidic sizing agents (rosin) are believed to be adsorbed on fiber surfaces by physical attraction (electrostatic attraction and van der Waal's force $)^{7), 8)}$, but alkaline sizing agents (AKD) are said to deposit on fiber surfaces by chemical means, for example, by the covalent bondings of beta-keto ester formation ${ }^{9), 10)}$. If there is a difference between the mechanism of acidic and 
alkaline sizing, it is quite possible that the stretching, especially the irreversible straing will causes a difference in the sizing efficiency between the rosin-sized and AKD-sized papers. Therefore, in this paper, effects of stretching on paper sizing were investigated.

\section{EXPERIMENTAL}

\subsection{Test specimens}

Commercial fine and wood containing acidicsized papers as well as pilot machine-made alkalinesized papers (AKD: Alkyl ketene dimer 0.2\%, Kymene $0.5 \%$, supplied by DIC-Hercules Co. Ltd.) were used for the test. Both acidic- (rosin 2\%, alum $4 \%$ ) and alkaline- (Alkyl ketene dimer $0.2 \%$, Kymene $0.5 \%$ ) sized handsheets were also used to ascertain the experimental results for the machine-made papers.

Test specimens were carefully prepared because the relatively large variation of sizing degree was present even within the same series of sheet. Samples were always taken from a neighboring position in the same sheet.

\subsection{Stretching of specimens}

Samples of $12 \times 12 \mathrm{~cm}$, and $4 \times 12 \mathrm{~cm}$ were stretched in machine direction (MD) and crossmachine direction (CD) separately as shown in Fig. 1 using the Instron type tensile tester to a pre-determined strain level, then the load was released. The samples for the Cobb sizing test are too large to clamp into the jaws, therefore, the sheet was folded at the two ends and then the half was stretched. All the stretched samples were reconditioned for 2 to 4 hours after unloading,
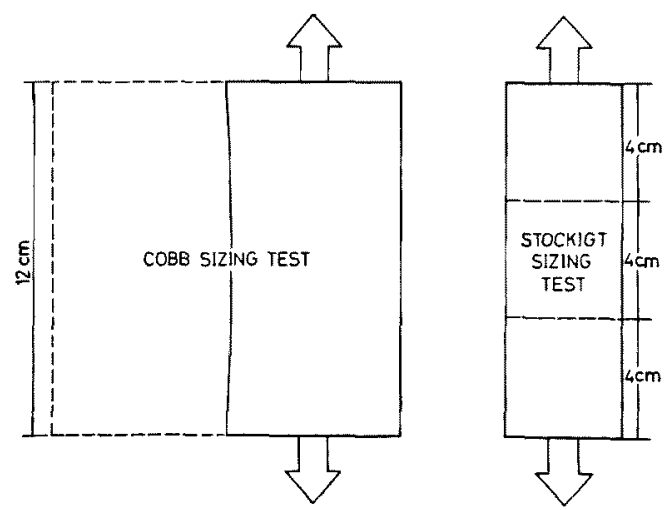

Fig. 1 Preparation of pre-strained sizing test samples. and then used for sizing tests. The elongation and residual strain of the samples were measured from the stress-strain curves on the charts.

\subsection{Measurement of sizing degree}

The Cobb sizing degree (TAPPI Standard T441 os-77) and the Stockigt sizing degree (JIS P81221976) were measured on the samples with and without pre-straining. As a method of evaluation of sizing degree, ultrasonic attenuation of the samples in water was also measured in the same way as described in a previous paper ${ }^{11}$. The data plotted are an average of at least 12 measurements.

\subsection{Measurement of specific light scattering coefficient and thickness}

The specific light scattering coefficient (expressed as $s$ ) of the sheet was measured according to JIS P8138-1976 using the Hunter reflectometer. The thickness was measured according to JIS P8118-1976 with the micrometer specially designed by Highbridge Co. Ltd. The light scattering coefficient and the thickness were measured on exactly the same area before and after stretching.

\section{RESULTS}

The stretched alkaline-sized papers showed lower Cobb sizing degrees than the unstretched ones, but the stretched acidic-sized ones showed a reverse tendency, though the changes were relatively small (Figs. 2 and 3). These findings suggest that the stretching of paper does affect sizing efficiency to certain extent, and the effect is different for acidic-sized and alkaline-sized papers.

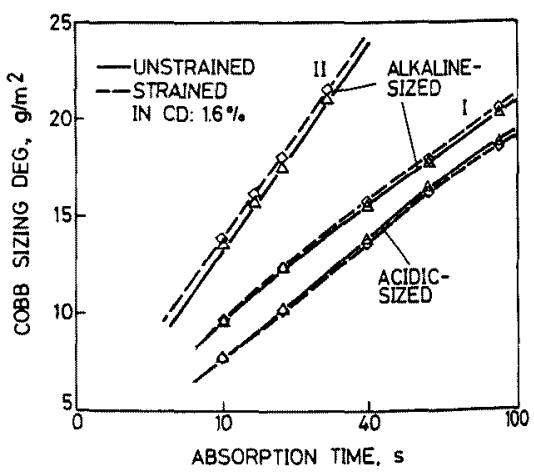

Fig. 2 Effect of pre-straining level on the Cobb sizing degree measured at varying absorption time.

I. Wood-free paper; II. Wood-containing paper, all the samples were strained in cross machine direction to $1.6 \%$. 


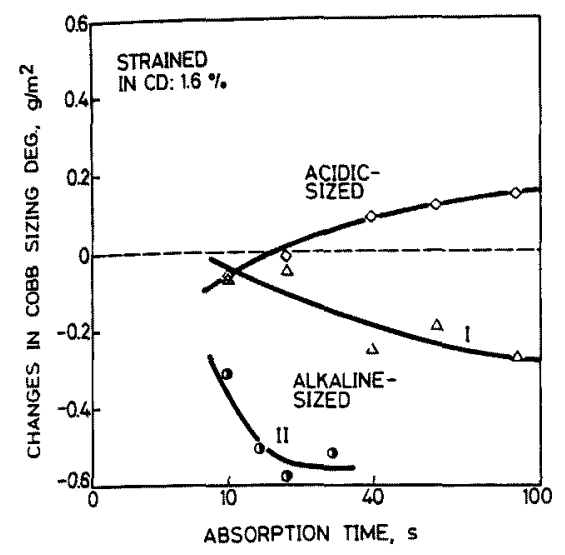

Fig. 3 Changes in Cobb sizing degree due to prestraining as a function of absorption time. I. Wood-free paper; II. Wood-containing paper

It is clearly seen from Fig. 3 that the Cobb sizing degree for strained wood-free paper decreases gradually with water absorption time, while that for wood-containing paper decreases rapidly with time and reaches an equilibrium level.

The amount of changes in Cobb sizing degree at an absorption of 60 seconds is shown in Fig. 4 . Obviously it varies with strain level. In the case of alkaline-sized paper, the sizing effect increases steadily to a certain level, that is, the Cobb values are reduced, then decreases with further straining.

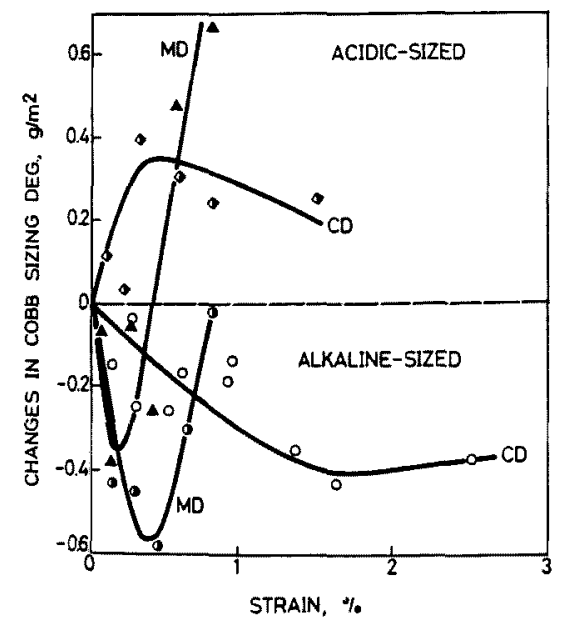

Fig. 4 Effect of pre-straining level of alkaline- and rosin sized fine papers on Cobb sizing degree.

Absorption time: 60 seconds.
In contrast to this finding, the sizing degree of acidic-sized papers decreases rapidly to a minimum level, then increases slowly. These curves have maximum values. The maxima appear at lower strain level for machine direction than for crossmachine direction. It is difficult now to elucidate the reason why the change in sizing degree has a maximum. A similar tendency was also observed in the measurement of Stockigt sizing degree as shown in Fig. 5. The fact that both the absorption(the Cobb test) and the penetration-type tests (the Stockigt test) show similar results indicates that accelerating or retarding the rate of liquid penetration into paper is attributable to changes in sheet structure caused by stretching.

It is well-known that machine-made paper have anisotropic mechanical and physical properties due to anisotropic fiber orientation and the drying-instress. When paper is strained in MD, it commonly shows greater tensile strength and lower strain level of strain-to-failure than when strained in $\mathrm{CD}$. The effect of stretching in $\mathrm{MD}$ and $\mathrm{CD}$ on sizing degree is also shown in Fig. 4. Apparently, small strain in MD leads to greater changes in sizing degree for both acidic-sized and alkaline-sized paper sheets. The ultrasonic attenuation of paper in water (Fig. 6) also showed a similar tendency. All these observations suggest that sizing degree does not solely depend on the amount of sizing agents, but also on the sheet structural parameters.

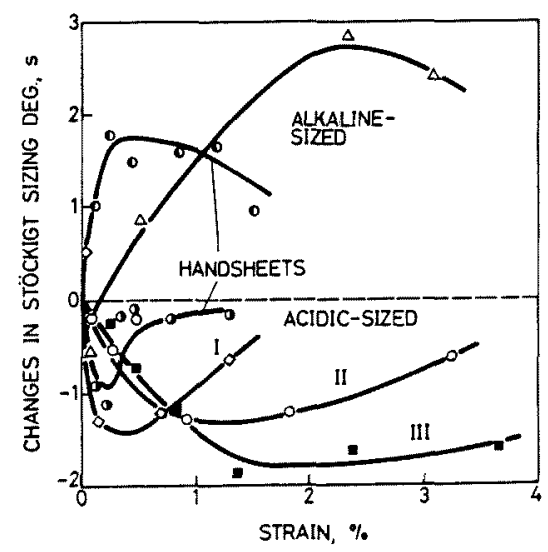

Fig. 5 Effect of pre-straining level of alkaline- and rosin sized papers on Stockigt sizing degree. I. Rosin sized fine paper; II and III. Rosin sized wood-containing papers. 


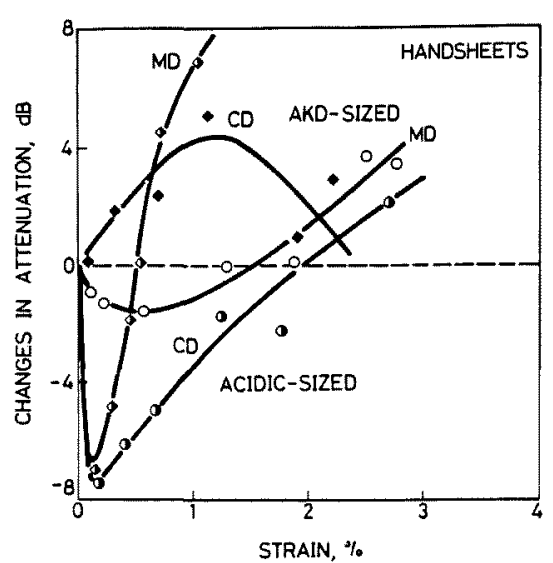

Fig. 6 Effect of pre-straining level of both AKDand rosin sized anisotropic handsheets on ultrasonic attenuation measured in water.

\section{DISCUSSION}

\subsection{Analysis of the factors affecting paper sizing}

In general, sizing efficiency of paper can be theoretically explained in terms of the LucasWashburn equation expressed as follows:

$$
h^{2}=\frac{r r \cos \theta}{2 \eta} t
$$

where, $h$ : penetration depth, $\mathrm{m}$

$r$ : surface tension of liquid, $\mathrm{N} / \mathrm{m}$

$r:$ radius of capillary, $m$

$\theta$ contact angle between liquid and paper surface

$\eta$ : viscosity of liquid, $\mathrm{P}$

$t$ : penetration time, s.

Usually, $t$ or some other factors relating to $t$ are measured as indications of sizing degree. The factors which vary with pre-straining and affect the sizing efficiency are paper thickness (capillary length), sheet porous structure (radius of capillary), and contact angle $(\theta)$.

According to Eq. (1), Stockigt sizing degree $(t)$ increases with an increase in thickness (relating to $h$ ) squared. Thickness variation of paper on stretching was reported to involve a complicated change in sheet structure ${ }^{1)}$. Generally, no practical change in sheet thickness is observed at lower levels of straining, but an evident increase can be recognized at higher levels of straining, especially at the straining level just before the rupture elongation ${ }^{1)}$.
That effect of changes in sheet thickness on Stockigt sizing degree is of limited significance could be supported by the comparison of the results in Fig. 4 by the Cobb test with those in Fig. 5. Cobb sizing degree is not affected by sheet thickness because this test measures only the amount of absorbed water in a fixed time. A similarity of the results by the two methods suggests that variation in thickness on straining is small and then not an important factor to sizing degree of strained paper.

\subsection{Effect of variation in sheet porous structure on sizing efficiency}

The straightening of longitudinally oriented fibers, the breakage of fiber bondings, and the formation of interfiber spaces are thought to occur on stretching. These phenomena bring about the structural changes such as sheet density or pore structure. These structural changes affect the sizing efficiency of strained papers.

Specific light scattering coefficient $(s)$ of a paper sheet is not only an index of fiber bondings, but also an indirect index of pore volume ${ }^{12-14)}$, which directly affects absorption properties of paper sheets. Since the measurement of $s$ is much easier than the measurement of pore volume $(\boldsymbol{r})$. In this study, $s$ is used to evaluate the changes in sheet structure due to stretching.

As shown in Fig. 7, $s$ responds obviously with the level of straining. For alkaline-sized sheets, $s$ tends to decrease a little at the beginning of straining, and then increases linearly with further

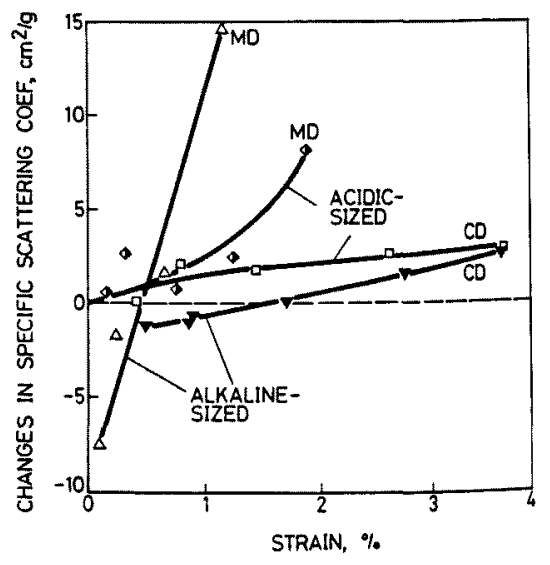

Fig. 7 Variation in light scattering coefficient as a function of pre-straining level of both alkaline- and rosin sized papers. 
straining. For acidic-sized papers, no decrease in $s$ was observed. This is probably due to the difference in bonding forces between pulp fibers and sizing agents.

No reports were found relating sizing efficiency to the light scattering coefficient of sheets so far. The present experiment was carried out with a view to understand this relationship. Generally, wet press and beating lead to reduction in $s$ of a sheet. Consequently, a series of handsheets with different wet pressing pressures and beating levels were prepared. The Stockigt sizing degree and Cobb sizing degree of alkaline-sized papers as a function of $s$ are shown in Figs. 8 and 9 respectively. Apparently, both figures show that increases

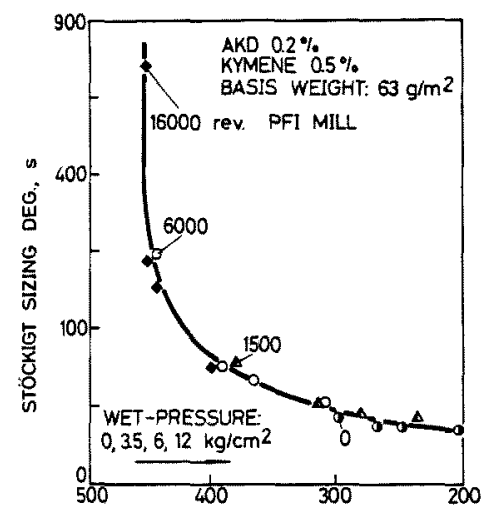

SPECIFIC SCATTERING COEF. $\mathrm{cm}^{2} / \mathrm{g}$

Fig. 8 Stockigt sizing degree as a function of light scattering coefficient of alkaline-sized handsheets.

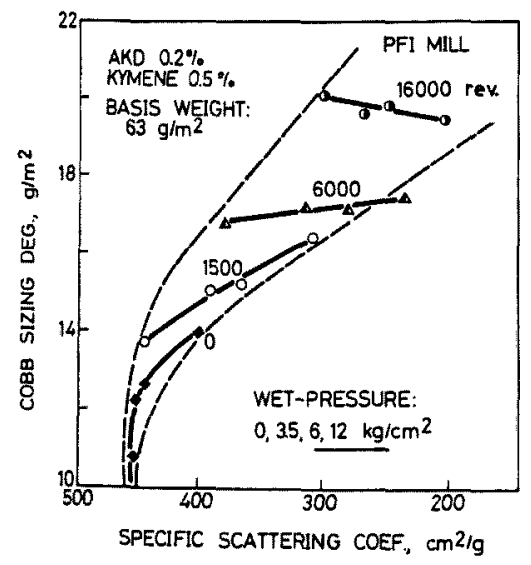

Fig. 9 Cobb sizing degree ( 60 seconds) as a function of specific light scattering coefficient of alkaline-sized handsheets. in fiber bondings and apparent density (decrease in $s$ and thickness) bring about a sharp decrease in sizing efficiency except for the case of Cobb sizing degree at very high beating level. The rosin sized papers showed the similar tendency. These findings, therefore, indicate that the increases in $s$ should bring about positive effect for both kinds of papers. However, the sizing efficiency of rosin sized paper decreases with straining regardless of an increase in $s$. This is not consistent with the results shown in Figs. 8 and 9. It is clear that the main factor which affects the changes in sizing efficiency by pre-straining is not the changes in $s$, but factors other than $s$ are involved.

\subsection{Difference between acidic-sized and alkaline- sized papers}

The surface tension of sheet materials is the key factor of hydrophobicity or sizing efficiency of papers. The purpose of paper sizing, therefore, is to cover the hydrophilic fiber surfaces (that is, cellulose and hemicellulose) with materials of lower surface tension. For a sized sheet, the following formula holds usually ${ }^{15}$.

$$
r_{\text {paper }}=A_{\text {size }} r_{\text {size }}+A_{\text {fiber }} \gamma_{\text {fiber }},
$$

where, $r$ is surface tension, $A$ expresses the ratio of the surface area $\left(F_{i}\right)$ of each component to total surface area $(F)$ of the paper. Consequently, a better sized sheet should possess as large $A_{\text {size }}$ as possible.

Increase in $s$ with strain (Fig. 7) indicates a formation of new inter- or intra-fiber surface area (expressed as $\left.F_{\text {new }}\right)$ due to straining. If $F_{\text {new }}$ has the similar property to fiber surface $\left(F_{\text {fiber }}\right)$, the sizing effect of strained papers will be reduced. On the contrary, if $F_{\text {new }}$ plays the same role as $F_{\text {size, }}$, the sizing effect of the paper will be improved on straining. The sizing efficiency decreased with straining for acidic-sized paper, This suggests that $F_{\text {new }}$ formed by stretching has lower sizing effect. Therefore, the facts indicate a removal of part of rosin size particles from fiber surfaces. Since the bonding forces between them is said to be a weak physical attraction, the above interpretation could be conceivable.

For alkaline-sized papers, pre-straining improved the sizing efficiency to some extent, which indicates that the $F_{\text {new }}$ have the similar property to $F_{\text {size }}$. In other words, the alkaline-sized fiber 
surfaces are less affected by the straining process. Therefore, it could be said here that the bondings between cellulosic fiber surfaces and AKD (or other reactive type sizing agents) are stronger than those between fiber surfaces and rosin, though the real bondings between cellulose and AKD have not been completely understood ${ }^{10), 16)}$.

In addition to the factor of $F_{\text {new }}$ described above, the increase in $s$ due to straining also leads an increase in the sizing effect. In the case of alkaline-sized papers, changes in $s$ have the same tendency with the increasing in sizing effect of strained papers. So it is assumed that, both the change in $s$ and the properties of newly formed surface $\left(F_{\text {new }}\right)$ are the factors of the sizing efficiency of pre-strained papers. For acidic-sized papers, the positive effect on the sizing efficiency due to increase in $s$ seems to be smaller than the effect of surface properties.

\section{CONCLUSION}

Effect of pre-straining of paper sheets on their sizing efficiency was studied. In general, the sizing efficiency decreased with straining for rosin sized papers and increased for alkaline-sized papers. However, these changes are relatively small (less than 10 percent of its original sizing degree). Analysis of the characteristics of strained papers revealed that changes in the size-covering ratio due to the newly formed surfaces on straining are the key factors to the sizing efficiency of an acidic-sized paper. But it seems less important to that of alkaline-sized papers because of a more uniform distribution and the stronger bondings of reactive size to fiber surfaces than rosin. For alkaline-sized one, an increase in $s$ due to prestraining seems to be an important factor affecting paper sizing.

\section{ACKNOWLEDGMENT}

The authors are grateful to DIC-Hercules Co. Ltd for supplying us the AKD sizing agents.

\section{REFERENCES}

1) O. E. Ohrn, Svensk Papperstidn., 68(5): 141-149 (1965)

2) J. A. Van den Akker, Tappi, 52 (12): 2386 2389 (1969).

3) J.P. Casey, "Pulp and Paper," Wiley-Interscience, New York, Vol. 3, pp. 1548-1549, 1981.

4) W. S. Wilson and H. E. Duston, Paper Trade J., $117(2): 223$ (Nov. 18, 1943).

5) H. F. Rance, The Paper-Maker and British Paper Trade J., p. 22-51 (1949).

6) T. Nakamura, "Kaminosaizu (The Sizing of Paper)," Hokuo Syoseki Boeki K.K. p. 214217, 1970.

7) J.W. Swanson, "Internal sizing of Paper and Paperboard", TAPPI Monograph No.33, TAPPI Press, Atlanta, p. 54.

8) E. Strazdins, Tappi, $\mathbf{6 0}(10): \quad$ 102-105 (1977).

9) J.C. Roberts, D.N. Garner and U.D. Akpabio, in "The Raw Materials of Paper Making Process and the Properties of Paper", International Symposium, Oxford, pp. 815-837 (1985).

10) J. C. Roberts, D. N. Garner, Cellulose Chem. Technol., 18: 275-282 (1984).

11) Y. L. Pan, S. Kuga, M. Usuda and T. Kadoya, Tappi; 68 (9): 98-101 (1985).

12) W. R. Haselton, Tappi, 37 (8): 404-412 (1954).

13) W. R. Haselton, Tappi, 38 (12): 716-723 (1955).

14) J. E. Stone and A. M. Scallan, Pulp and Paper Mag. Can., 66 (8): T407-T414 (1965).

15) R. G. Guide, Tappi, 42 (9): 740-746 (1959)

16) R. Peter, B. Michal and P. W. Dietrich, Tappi, 68(1): 83-86 (1959).

\section{サイズ特性に対する紙シートの歪前処理の影響*1}

歪み与ええた紙のサイズ特性をステキヒトおよびコッ ブサイズ度試験法により測定を行なった。酸性紙の場合, サイズ効果は歪み処理により低下するが，中性紙の場合 は逆に增加し，紙の種類には関係せず，サイズ効果が歪 みの大きさに依存している現象か認められた。Lucas ${ }^{* 1}$ 本報文の一部は第 36 回木材学会大会 (1986 年4月,静 岡大学)に拈いて発表した。

\section{東京大学農学部墦 雲龍, 尾鍋史彦, 臼田誠人}

Washburnの式に基づき歪前処理により影響される維の 厚さ、シートの空隙構造およびサイズ剂の織維表面で 分布などの因子に着目し，サイズ効果への影暨を梌討し た。その結果，サイズ刘の織維表面での定着力およびサ

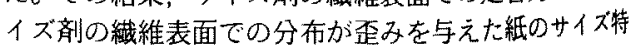
性にとって重要であるてとがわかった。 